\title{
Biventricular repair in patients with heterotaxy syndrome
}

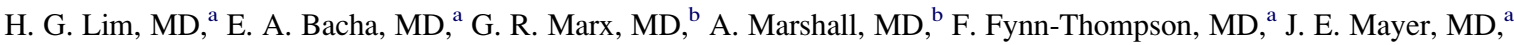 \\ P. Del Nido, MD, and F. A. Pigula, MD $^{\mathrm{a}}$
}

Objective: Complex intracardiac and extracardiac anatomy is often confronted during biventricular repair in patients with heterotaxy syndrome. We examined factors affecting surgical outcomes in these patients.

Methods: Between January 1990 and July 2007, 371 patients received a diagnosis of heterotaxy syndrome; 91 $(91 / 371,24.5 \%)$ underwent biventricular repair. Left atrial isomerism was present in 73\% (66/91) and right atrial isomerism in 10\% (9/91), with indeterminate atrial anatomy in 17\% (16/91). Median age at biventricular repair was 6.8 months ( 5 days to 22.3 years). Systemic venous anomalies were present in 75 patients, pulmonary venous anomalies in 26, and endocardial cushion defects in 36. Transposition complexes were present in 15 patients with atrioventricular discordance in 10; 8 underwent double switch, 2 received a physiologic repair, 2 underwent arterial switch, and 3 underwent the Rastelli operation. Other conotruncal anomalies included double-outlet right ventricle in 10 patients, tetralogy of Fallot in 3, and hemitruncus in 2. Separation of systemic from pulmonary venous return included intra-atrial baffling in 48 patients and extracardiac grafting in 2. Combined lesions were common, occurring in 99\% (90/91). Statistical analysis with Kaplan-Meier and Cox proportional hazards models were performed.

Results: Average follow-up was $44.9 \pm 57.5$ months ( 3 days to 189.3 months). Kaplan-Meier estimated survival was $93.4 \%$ at 10 years; unbalanced complete atrioventricular canal was the only risk factor for mortality $(P=$ .006). Subsequent procedures were common with a 10-year freedom from reoperation or reintervention of $38 \% \pm 7.5 \%$. Arrhythmias occurred in $36(39.6 \%)$ patients; bradyarrhythmia in $27(29.7 \%)$ and tachyarrhythmia in $15(16.5 \%)$. Freedom from any arrhythmia was $53.9 \% \pm 6.7 \%$ at 10 years.

Conclusions: Excellent survival for patients with heterotaxy undergoing biventricular repair can be expected, even for multiple, complex lesions. Reintervention is common, and arrhythmia is a long-term concern. This experience shows that patients with heterotaxy syndrome and complex cardiac anatomy can be considered for biventricular repair. Patients with unbalanced complete atrioventricular canal are a high-risk group for which selection criteria are particularly important.

\section{Supplemental material is available online.}

Anatomic complexity and variability are hallmarks of cardiac disease associated with visceroatrial heterotaxy syndrome (heterotaxy syndrome). Because of anatomic constraints, single ventricle palliation is the only option for many of these patients. Although recent reports suggest improving surgical survival among patients with heterotaxy undergoing the Fontan operation, late morbidity and mortality remain problems. ${ }^{1-3}$

Although single ventricle palliation is unavoidable for many patients, a subset of heterotaxy patients will have anat-

\footnotetext{
From the Departments of Cardiac Surgery ${ }^{\mathrm{a}}$ and Cardiology, ${ }^{\mathrm{b}}$ Children's Hospital of Boston, Harvard Medical School, Boston, Mass.

Read at the Eighty-eighth Annual Meeting of The American Association for Thoracic Surgery, San Diego, Calif, May 10-14, 2008.

Received for publication May 16, 2008; revisions received Oct 1, 2008; accepted for publication Oct 26, 2008

Address for reprints: Frank A. Pigula, MD, Children's Hospital of Boston, Department of Cardiothoracic Surgery, 300 Longwood Ave, Farley 144, Boston, MA 02115 (E-mail: Frank.pigula@tch.harvard.edu).

J Thorac Cardiovasc Surg 2009;137:371-9

$0022-5223 / \$ 36.00$

Copyright (C) 2009 by The American Association for Thoracic Surgery

doi:10.1016/j.jtcvs.2008.10.027
}

omy that may be suitable for biventricular repair. ${ }^{4-7}$ The present study seeks to determine the frequency of biventricular repair for heterotaxy syndrome at our institution and to analyze the anatomic factors that predict outcomes after biventricular repair. Specifically, we examined early and late survival, arrhythmia, functional status, residual lesions, and freedom from reintervention or reoperation.

\section{PATIENTS AND METHODS}

The databases of the Departments of Cardiology and Cardiac Surgery, Children's Hospital Boston, were searched for patients with heterotaxy syndrome who had undergone a biventricular repair. Institutional review board approval was granted and patient consent was waived for this retrospective study. Between January 1990 and July 2007, 371 patients with heterotaxy syndrome were treated surgically with single $(n=280,75.5 \%)$ or biventricular repair $(n=91,24.5 \%)$. To date, single ventricle palliation has culminated in 177 Fontan operations, with the remaining 103 patients currently at an intermediate stage of single ventricle palliation. Ninety-one patients were considered suitable for biventricular repair. The median age at the time of repair was 6.8 months (range, 5 days to 22.3 years); 34 $(37.4 \%)$ were male and $57(62.6 \%)$ were female. The mean follow-up period was $44.9 \pm 57.5$ months (range, 3 days to 189.3 months).

\section{Definitions}

$\mathrm{We}^{2}$ have defined heterotaxy syndrome as the presence of a pattern of typical cardiac, vascular, and visceral abnormalities that indicated abnormal sidedness. Heterotaxy syndrome is largely synonymous with the syndromes 


\author{
Abbreviations and Acronyms \\ AICD = automatic implantable \\ cardioverter defibrillator \\ $\mathrm{AV}=$ atrioventricular \\ $\mathrm{CAVC}=$ complete atrioventricular canal \\ $\mathrm{DORV}=$ double-outlet right ventricle \\ IVC = inferior vena cava \\ NYHA $=$ New York Heart Association \\ $\mathrm{RVOT}=$ right ventricular outflow tract \\ SVC = superior vena cava \\ VSD $=$ ventricular septal defect
}

known as left or right atrial isomerism or asplenia or polysplenia syndrome. Clinically, we have chosen atrial morphology as the primary classification index. If the atrial morphology was ambiguous, these patients were classified as having "indeterminate" anatomy.

Although cardiac malformations associated with heterotaxy syndrome are prone to clustering, they show considerable overlap that often defies clear classification. For this reason, patients were considered to have indeterminate atrial anatomy if, by surgical inspection, atrial isomerism was not clearly identifiable and if other findings typical of polysplenia or asplenia were not identified during cardiac evaluations.

Tachyarrhythmia was defined as the presence of documented atrial fibrillation, atrial flutter, atrioventricular (AV) reciprocating tachycardia, ectopic atrial tachycardia, accelerated junctional rhythm, ventricular tachycardia, or ventricular fibrillation, but not sinus tachycardia. Bradyarrhythmia included sinus bradycardia, abrupt and pronounced sinus pause or arrest, sick sinus syndrome, slow junctional escape rhythm, junctional rhythm at physiologic rates without evidence of sinus node activity, and second- or third-degree AV block. All arrhythmias that were reported in the charts were noted, without attempt to determine clinical impact. This definition includes even brief periods of intraoperative or early postoperative arrhythmia that resolved spontaneously and did not recur.

\section{Anatomy}

On the basis of surgical and echocardiographic evaluations, 9 patients $(9 / 91,10 \%)$ had right atrial isomerism, 66 patients $(66 / 91,72.5 \%)$ had left atrial isomerism, and 16 patients $(16 / 91,17.6 \%)$ had ambiguous atrial anatomy and were classified as having "indeterminate" anatomy. These patients were distinguished by the wide variability in associated cardiac lesions; however, in general they could be assigned to abnormalities of the endocardial cushion, septal defects, and conotruncal abnormalities (Table 1).

Cardiac malposition was also common, and dextrocardia was present in $23 \%$ (21/91). Ten patients with complete AV canal defect (CAVC) were diagnosed with an unbalanced AV valve orifice favoring the morphologically right ventricle in 7 and left ventricle in 3 .

Thirty-six $(28 \%)$ patients had a common AV valve; moderate or greater $\mathrm{AV}$ valve regurgitation was demonstrated by echocardiography or catheterization in $28 \%$ (10/36). Transposition complexes were present in 15 $(16.5 \%)$ patients and normally related great vessels were present in 66 $(72.5 \%)$ Ten $(11 \%)$ patients were diagnosed with double-outlet right ventricle (DORV) with muscular outlet conus under each great vessel, which was usually associated with pulmonary stenosis $(n=7)$ or atresia $(n=2)$. Some of these patients were the subject of a previous report from our institution. ${ }^{8}$

Abnormalities of pulmonary venous connections were present in $26 \%$ (24/91) of patients, and systemic venous abnormalities were identified in $82 \%$ (75/91) of patients. Forty-nine $(53.9 \%)$ patients had bilateral superior vena cava (SVC), usually without a connecting innominate vein, and 61 $(67.0 \%)$ patients had an interrupted inferior vena cava (IVC) with azygos continuation. Combined lesions were very common, occurring in $99 \%$ (90/91) of patients.

\section{Surgical Treatment}

Twenty-three patients underwent 43 procedures before repair. Twenty of these procedures were related to optimizing pulmonary blood flow with a pulmonary artery band or shunt, whereas most of the remaining pre-repair procedures involved repair of anomalous pulmonary venous connections (Appendix E1).

The biventricular repair was accomplished anatomically with the left ventricle used as the systemic ventricle in 89 patients; a physiologic repair with the right ventricle used as the systemic ventricle was done in 2 .

Among the 10 patients with L-transposition of the great arteries, anatomic repair included a double switch operation in 8 patients; Senning and Rastelli procedures in 4; Mustard and Rastelli procedures in 1; Mustard and arterial switch in 2; and intra-atrial baffling of a left SVC, repair of total anomalous pulmonary venous return, and Rastelli procedure in 1 . The physiologic repair was achieved by ventricular septal defect (VSD) closure with insertion of a left ventricle-pulmonary artery conduit in 2 patients with L-transposition and pulmonary atresia.

Among the 5 patients with D-transposition of the great arteries, the arterial switch operation was performed in 2, and the Rastelli procedure was performed in 3. One patient with DORV and subpulmonic VSD also underwent an arterial switch operation.

Atrial septation, resulting in exclusive atrial drainage to a dedicated ventricle, was required in 50 patients. It required intra-atrial baffling in 41 patients (ie, unroofed coronary sinus, left SVC), atrial switch in 7, and extracardiac graft interposition in 2.

\section{Statistical Analysis}

Statistical analyses were performed with SPSS version 14.0 software (SPSS, Inc, Chicago, Ill). Data were presented as a mean \pm standard deviation or a median with ranges as appropriate. Simple binomial proportions were compared by Fisher's exact test. Estimated survival and freedom from reintervention, reoperation, tachyarrhythmia, and bradyarrhythmia were determined by the Kaplan-Meier method. Variables were evaluated by the likelihood ratio test in the Cox proportional hazards regression model. Hazard ratios with $95 \%$ confidence intervals were constructed for the significant multivariable predictors. All of the analyzed data were selected on the basis of a review of medical records, operative notes, all available electrocardiograms, echocardiography reports, and cardiac catheterization reports. The follow-up status of patients was determined by retrospective review of hospital records.

\section{RESULTS}

There were 2 early deaths $(2.2 \%)$. One patient with left atrial isomerism underwent total repair of unbalanced CAVC with tetralogy of Fallot. The initial operation included a transannular patch for relief of right ventricular outflow tract (RVOT) obstruction, followed by reoperation for ligation of aortopulmonary collaterals and the insertion of a valved right ventricle-pulmonary artery conduit. The patient died of ischemic brain injury 20 days after the operation. One patient with left atrial isomerism underwent total repair for coarctation of aorta and unbalanced CAVC at 6 days of age. After a two-patch repair, she required reoperation 1 week later for dehiscence of the AV valve tissue from the VSD patch and died of sepsis 43 days after the operation.

There were $2(2.2 \%)$ late deaths. One patient with left isomerism underwent total repair for DORV and CAVC at 8 months of age after pulmonary artery banding and 
TABLE 1. Anatomic findings in patients undergoing biventricular repair for heterotaxy syndrome

\begin{tabular}{|c|c|c|c|c|c|}
\hline Type & Morphology & Heterotaxy $(\mathrm{n}=91)$ & Lt. isomerism $(n=66)$ & Rt. isomerism $(n=9)$ & Indeterminate $(\mathrm{n}=16)$ \\
\hline \multirow[t]{4}{*}{ Ventricle } & Two ventricle & $81(89.0 \%)$ & $59(89.4 \%)$ & $8(88.9 \%)$ & $14(87.5 \%)$ \\
\hline & Unbalanced & $10(11.0 \%)$ & $7(10.6 \%)$ & $1(11.1 \%)$ & $2(12.5 \%)$ \\
\hline & Rt. dominant & 7 & 5 & 1 & 1 \\
\hline & Lt. dominant & 3 & 2 & 0 & 1 \\
\hline \multirow[t]{5}{*}{ PV } & TAPVR & $10(11.0 \%)$ & $6(9.1 \%)$ & $3(33.3 \%)$ & $1(6.3 \%)$ \\
\hline & Supracardiac & 3 & 2 & 1 & 0 \\
\hline & Intracardiac & 6 & 4 & 1 & 1 \\
\hline & Infracardiac & 1 & 0 & 1 & 0 \\
\hline & PAPVR & $16(17.6 \%)$ & $14(21.2 \%)$ & $0(0 \%)$ & $2(12.5 \%)$ \\
\hline \multirow[t]{3}{*}{ VA } & Concordance & $66(72.5 \%)$ & $56(84.9 \%)$ & $2(22.2 \%)$ & $8(50.0 \%)$ \\
\hline & Discordance & $15(16.5 \%)$ & $5(7.6 \%)$ & $6(66.7 \%)$ & $4(25.0 \%)$ \\
\hline & DORV & $10(11.0 \%)$ & $5(7.6 \%)$ & $1(11.1 \%)$ & $4(25.0 \%)$ \\
\hline \multirow[t]{2}{*}{ PA } & Atresia & $9(9.9 \%)$ & $3(4.6 \%)$ & $4(44.4 \%)$ & $2(12.5 \%)$ \\
\hline & Stenosis & $20(22.0 \%)$ & $12(18.2 \%)$ & $2(22.2 \%)$ & $6(37.5 \%)$ \\
\hline \multirow[t]{3}{*}{ SVC } & Bilateral SVC & $49(53.9 \%)$ & $39(59.1 \%)$ & $7(77.8 \%)$ & $3(18.8 \%)$ \\
\hline & Right SVC & $27(29.7 \%)$ & $16(24.2 \%)$ & $1(11.1 \%)$ & $10(62.5 \%)$ \\
\hline & Left SVC & $15(16.5 \%)$ & $11(16.7 \%)$ & $1(11.1 \%)$ & $3(18.8 \%)$ \\
\hline \multirow[t]{3}{*}{ IVC } & Right IVC & $19(20.9 \%)$ & $5(7.6 \%)$ & $4(44.4 \%)$ & $10(62.5 \%)$ \\
\hline & Left IVC & $9(9.9 \%)$ & $0(0 \%)$ & $4(44.4 \%)$ & $5(31.3 \%)$ \\
\hline & IVC absence & $61(67.0 \%)$ & $60(90.9 \%)$ & $1(11.1 \%)$ & $0(0 \%)$ \\
\hline
\end{tabular}

$P V$, Pulmonary vein; $T A P V R$, total anomalous pulmonary venous return; $P A P V R$, partial anomalous pulmonary venous return; $V A$, ventriculoarterial; $D O R V$, double-outlet of right ventricle; $P A$, pulmonary artery; $S V C$, superior vena cava; $I V C$, inferior vena cava.

permanent pacemaker implantation; this patient died of neurologic complication 101 days later after cardiac catheterization. One patient with left atrial isomerism underwent VSD closure at 4 months of age and died of end-stage liver disease and sepsis resulting from extrahepatic biliary atresia 167 days after the operation.

Kaplan-Meier estimated survival for the entire cohort was $93.4 \% \pm 3.2 \%$ at $1,5,10$, and 15 years (Figure 1 ).
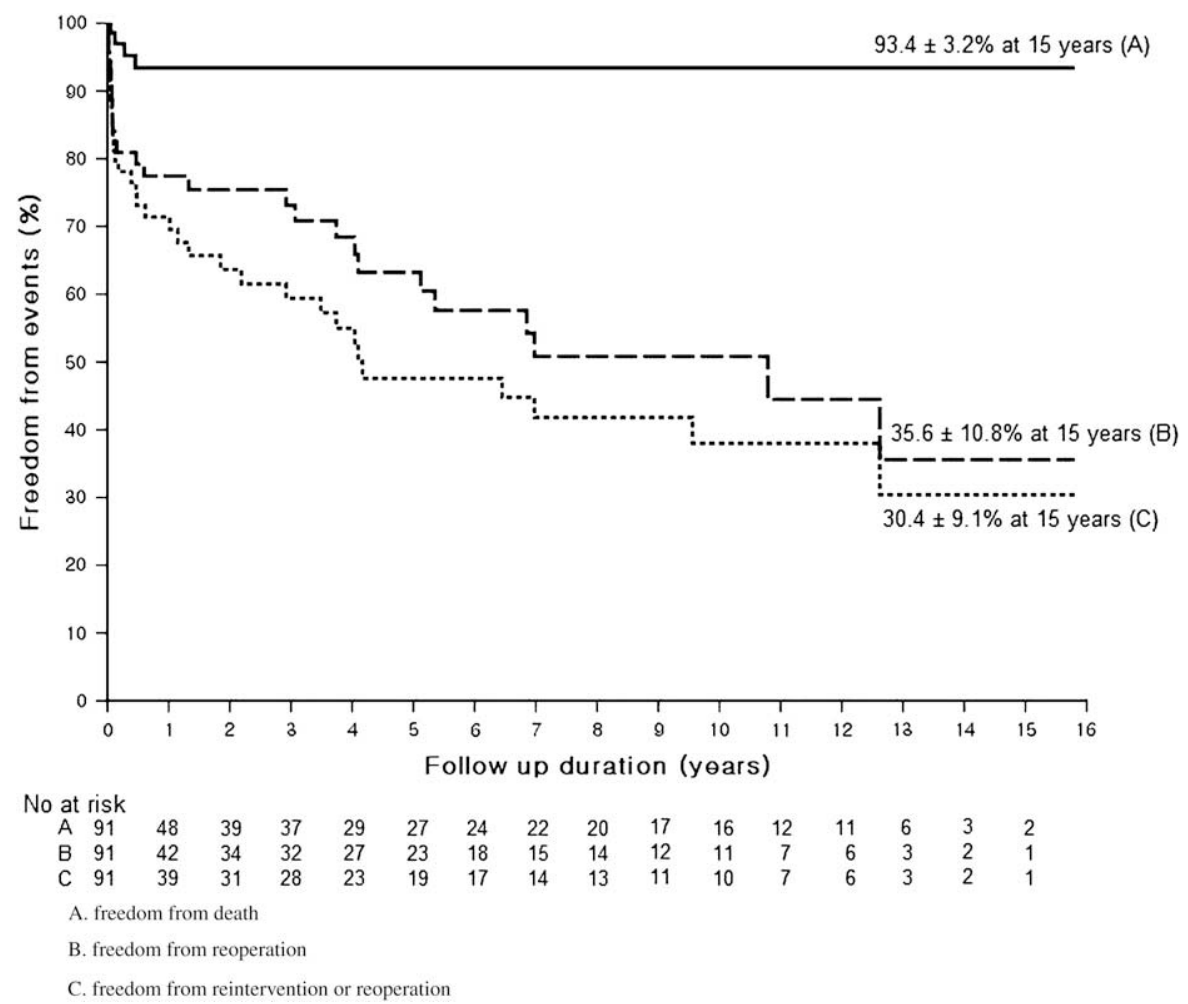

FIGURE 1. Freedom from deaths (A), reoperation (B), and reinterventions (C) after biventricular repair in patients with heterotaxy syndrome. 
Multivariable analysis identified the presence of an unbalanced ventricle as an independent risk factor for death (hazard ratio $=29.616 ; P=.006$ ) (Table 2). The designation of "unbalanced ventricle" was made by the attending cardiologist on the basis of the information accumulated from the imaging studies regarding left ventricular size, papillary muscle number and location, and the amount of AV valve tissue dedicated to each ventricle. Other variables examined, such as the presence of a preoperative shunt, pulmonary artery banding, type of isomerism, common AV valve, preoperative $\mathrm{AV}$ valve regurgitation of at least moderate degree, ventriculoarterial connection, total anomalous pulmonary venous return, pulmonary atresia/stenosis, and bilateral SVC and IVC interruption, were not statistically significant risk factors for death.

Postoperative delayed sternal closure was needed in 9 patients, ranging in age from 6 days to 58 months of age, and extracorporeal membrane oxygenation support was required in 4 . The other postoperative complications included renal failure in 3 , postoperative bleeding in 3 , chylous pleural effusion in 3 , sepsis in 2 , brain injury in 2 , pneumothorax in 2, postcardiotomy failure in 1, endocarditis in 1, pneumonia in 1 , wound infection in 1 , pericardial effusion in 1 , and pneumoperitoneum of unknown etiology in 1.

\section{Reoperations}

Thirty-seven reoperations were required in $28(30.8 \%)$ patients at an average of $29.4 \pm 41.5$ months ( 2 days to 151.1 months, Table 2) after repair (Appendix E2). More than half of the reoperations were for repair/replacement of the AV valves, revision of the RVOT, or for placement of a pacemaker.

Freedom from reoperation was $77.5 \% \pm 5.1 \%$ at 1 year, $63.2 \% \pm 6.7 \%$ at 5 years, $50.8 \% \pm 7.8 \%$ at 10 years, and $35.6 \% \pm 10.8 \%$ at 15 years.

\section{Catheter Reintervention}

Thirty reinterventions were required in 21 patients (21/91, $23.1 \%$ ) an average of $29.0 \pm 32.5$ months (15 days to 114.5 months) after repair (Appendix E3). Catheter reintervention was most commonly performed for relief of RVOT stenosis and for a smaller number of residual septal defects and rhythm disturbances. Two patients had aortopulmonary collaterals, and both required postoperative catheter occlusion. Freedom from reintervention was $84.9 \% \pm 4.7 \%$ at 1 year, $65.4 \% \pm 7.1 \%$ at 5 years, $51.3 \% \pm 8.5 \%$ at 10 years, and $51.3 \% \pm 8.5 \%$ at 15 years.

Freedom from reintervention or reoperation was $71.4 \% \pm$ $5.5 \%$ at 1 year, $47.6 \% \pm 7.0 \%$ at 5 years, $38.0 \% \pm 7.5 \%$ at 10 years, and $30.4 \% \pm 9.1 \%$ at 15 years (Figure 1). Multivariable analysis using the Cox regression model indicated that pulmonary stenosis $(P=.001)$, pulmonary atresia $(P=.002)$, and the presence of a common AV valve $(P=$
$.008)$ were independent predictors for the need of reintervention and reoperation (Table 2).

\section{Arrhythmia}

Arrhythmias occurred in $36(39.6 \%)$ patients. Bradyarrhythmia occurred in $27(29.7 \%)$. A permanent pacemaker was implanted in 17 patients for one or more of the following indications: complete AV block in 10, sinus node dysfunction in 6, second-degree AV block in 2, third-degree AV block in 1 , and sinus bradycardia in 1 . The pacemaker was implanted preoperatively in 4 patients, intraoperatively in 7 , and after repair in 6. Junctional rhythm with sinus node dysfunction was observed in 8 patients, and transient complete AV block occurred in 2. Tachyarrhythmia occurred in $15(16.5 \%)$ patients. Ventricular tachycardia occurred in 5 patients, necessitating transvenous insertion of an automatic implantable cardioverter defibrillator (AICD) in 1 and radiofrequency ablation in 1 . Accelerated junctional rhythm occurred in 5, ectopic atrial tachycardia in 4, and ventricular fibrillation in 1 .

Freedom from tachyarrhythmia was $86.9 \% \pm 3.8 \%$ at 1 year, $86.9 \% \pm 3.8 \%$ at 5 years, $73.7 \% \pm 7.8 \%$ at 10 years, and $63.1 \% \pm 11.8 \%$ at 15 years. Freedom from bradyarrhythmia was $71.5 \% \pm 5.1 \%$ at 1 year, $65.3 \% \pm 6.3 \%$ at 5 years, $65.3 \% \pm 6.3 \%$ at 10 years, and $60.2 \% \pm 7.5 \%$ at 15 years. Freedom from overall arrhythmia was $62.7 \% \pm$ $5.5 \%$ at 1 year, $56.9 \% \pm 6.4 \%$ at 5 years, $53.9 \% \pm 6.7 \%$ at 10 years, and $41.2 \% \pm 9.8 \%$ at 15 years (Figure 2). Multivariable analysis using the Cox regression model indicated that pulmonary stenosis $(P=.038)$ was an independent predictor for bradyarrhythmia and that older age at biventricular repair $(P=.005)$ predicted tachyarrhythmia (Table 2$)$.

\section{Last Follow-up Status}

Last follow-up echocardiography results were available for $85(93.4 \%)$ patients at a mean follow-up of $42.2 \pm$ 56.2 months ( 1 day to 176.7 months). Sixteen (18.8\%) patients had residual lesions, which included moderate mitral regurgitation in 6 , moderate mitral stenosis in 2 , moderate conduit stenosis in 2, moderate tricuspid regurgitation in 2 , moderate-to-severe mitral regurgitation and moderate left ventricular dysfunction in 1 , pulmonary vein stenosis with moderate tricuspid regurgitation in 1 , moderate right ventricular dysfunction in 1, and residual VSD in 1. Information on functional status was available for 83 patients; $82(98.8 \%)$ met the criteria for the New York Heart Association (NYHA) functional class I; 1 patient had respiratory distress as a result of progressive pulmonary vein stenosis.

\section{DISCUSSION}

Although most children born with heterotaxy syndrome will require single ventricle palliation, a substantial minority will be candidates for biventricular repair. Analysis of these patients showed survival to be excellent but revealed that these patients are not free from 
TABLE 2. Predictors of mortality, arrhythmia, reintervention and reoperation after biventricular repair in patients with heterotaxy syndrome

\begin{tabular}{|c|c|c|c|c|c|}
\hline \multirow[b]{2}{*}{ Outcome } & \multirow[b]{2}{*}{ Variable } & \multirow{2}{*}{$\frac{\text { Univariable }}{P \text { value }}$} & \multicolumn{3}{|c|}{ Multivariable } \\
\hline & & & Hazard ratio & $95 \%$ CI & $P$ value \\
\hline \multirow[t]{11}{*}{ Mortality } & Preoperative shunt & .527 & & & .507 \\
\hline & Preoperative PA banding & .145 & 13.082 & $0.817-209.605$ & .069 \\
\hline & Type of isomerism & .499 & & & .629 \\
\hline & Unbalanced ventricle & .001 & 29.616 & $2.634-332.948$ & .006 \\
\hline & AV valve & .083 & & & .717 \\
\hline & AVVR $\geq$ moderate & .181 & & & .214 \\
\hline & Ventriculoarterial connection & .320 & & & .672 \\
\hline & TAPVR & .530 & & & .506 \\
\hline & Pulmonary atresia/stenosis & .860 & & & .314 \\
\hline & Bilateral SVC & .272 & & & .435 \\
\hline & IVC interruption & .181 & & & .121 \\
\hline \multirow[t]{13}{*}{ Reoperation or reintervention } & Preoperative shunt & .001 & & & .149 \\
\hline & Preoperative PA banding & .654 & & & .36 \\
\hline & Type of isomerism & .369 & & & .936 \\
\hline & Unbalanced ventricle & .005 & & & .537 \\
\hline & Common AV valve & .003 & 2.75 & $1.306-5.792$ & .008 \\
\hline & AVVR $\geq$ moderate & .269 & & & .908 \\
\hline & Ventriculoarterial connection & .001 & & & .331 \\
\hline & TAPVR & .747 & & & .959 \\
\hline & Pulmonary atresia/stenosis & .001 & & & .001 \\
\hline & Pulmonary stenosis & .001 & 4.467 & 2.019-9.882 & .001 \\
\hline & Pulmonary atresia & .093 & 5.470 & $1.849-16.183$ & .002 \\
\hline & Bilateral SVC & .076 & & & .238 \\
\hline & IVC interruption & .724 & & & .562 \\
\hline \multirow[t]{17}{*}{ Bradyarrhythmia } & Preoperative shunt & .938 & & & .894 \\
\hline & Preoperative PA banding & .929 & & & .909 \\
\hline & Type of isomerism & .886 & & & .937 \\
\hline & Unbalanced ventricle & .065 & & & .151 \\
\hline & AV valve & .273 & & & .510 \\
\hline & AVVR $\geq$ moderate & .969 & & & .969 \\
\hline & Ventriculoarterial connection & .850 & & & .492 \\
\hline & TAPVR & .840 & & & .933 \\
\hline & Pulmonary atresia/stenosis & .046 & & & .061 \\
\hline & Pulmonary stenosis & .018 & 2.332 & $1.050-5.179$ & .038 \\
\hline & Pulmonary atresia & .268 & 0.438 & $0.058-3.310$ & .424 \\
\hline & Bilateral SVC & .689 & & & .424 \\
\hline & IVC interruption & .765 & & & .653 \\
\hline & Age at operation & .425 & & & .285 \\
\hline & Type of atrial repair & .534 & & & .702 \\
\hline & Functional repair as systemic RV & .357 & & & .507 \\
\hline & One-and-one-half ventricular repair & .586 & & & .438 \\
\hline \multirow[t]{12}{*}{ Tachyarrhythmia } & Preoperative shunt & .805 & & & 621 \\
\hline & Preoperative PA banding & .865 & & & .883 \\
\hline & Type of isomerism & .112 & & & .171 \\
\hline & Unbalanced ventricle & .380 & & & .182 \\
\hline & AV valve & .704 & & & .824 \\
\hline & AVVR $\geq$ moderate & .596 & & & .408 \\
\hline & Ventriculoarterial connection & .068 & & & .202 \\
\hline & TAPVR & .371 & & & .603 \\
\hline & Pulmonary atresia/stenosis & .510 & & & .751 \\
\hline & Bilateral SVC & .825 & & & .843 \\
\hline & IVC interruption & .425 & & & .476 \\
\hline & Age at operation & .002 & 1.009 & $1.003-1.015$ & .005 \\
\hline
\end{tabular}


TABLE 2. Continued

\begin{tabular}{|c|c|c|c|c|c|}
\hline \multirow[b]{2}{*}{ Outcome } & \multirow[b]{2}{*}{ Variable } & \multirow{2}{*}{$\frac{\text { Univariable }}{P \text { value }}$} & \multicolumn{3}{|c|}{ Multivariable } \\
\hline & & & Hazard ratio & $\mathbf{9 5} \% \mathrm{CI}$ & $P$ value \\
\hline & Type of atrial repair & .578 & & & .609 \\
\hline & Functional repair as systemic RV & .424 & & & .441 \\
\hline & One-and-half ventricular repair & .704 & & & .744 \\
\hline
\end{tabular}

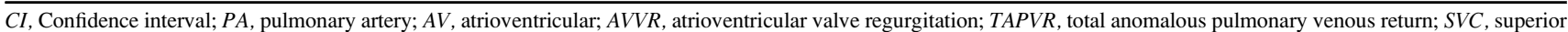
vena cava; $I V C$, inferior vena cava; $R V$, right ventricle.

the morbidities that plague heterotaxy patients with single ventricle physiology, primarily arrhythmias and reoperations.

Previous data from our institution reported that KaplanMeier estimated survival for patients undergoing the Fontan operation was $90 \%$ at 1 year and $87 \%$ at 10 years and is comparable with what $\mathrm{we}^{2}$ report for biventricular repairs (93\%). Although only $70 \%$ of Fontan patients with heterotaxy were considered to be in NYHA functional class I, $98 \%$ of assessed patients with biventricular repairs were in NYHA class I.

In contrast to the single ventricle experience, AV valve regurgitation and anomalous pulmonary venous connections were not found to be important contributors to mortality after biventricular repair. The only risk factor identified for mortality was the presence of unbalanced CAVC. Among 10 patients with unbalanced CAVC, there were 2 deaths (1 from sepsis, 1 from neurologic injury), despite evidence of an adequate cardiac repair. The nonsurvivors tended to be younger $(2.1 \pm 2.7$ months $)$ than survivors $(9 \pm 14.3$ months $)$ and required more procedures for repair (ie, CAVC, coarctation, left SVC baffle, $3.5 \pm 0.7)$ than did survivors (3.0 \pm $0.9)$, although neither difference was significant $(P>.5)$.

Although these 10 patients were considered to have "mildly" unbalanced ventricles, this is admittedly a qualitative designation, and no accepted criteria for the suitability of biventricular repair in the setting of "unbalanced" CAVC are easily applicable to the individual patient. For this reason, the decision to proceed with biventricular repair in these patients was determined on a case-by-case basis by the attending cardiologists and surgeon.

Although overall mortality was low, morbidity persists. The incidence of postoperative arrhythmia was significant compared with reports of heterotaxy patients undergoing

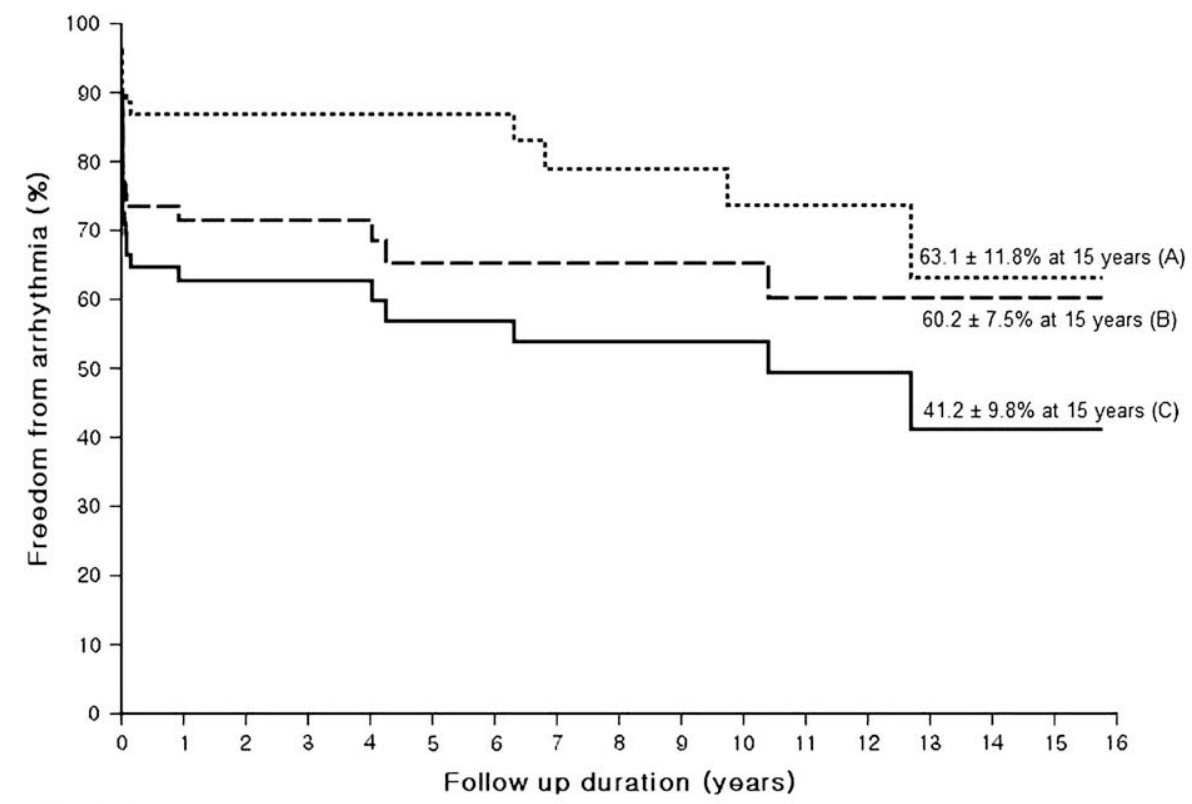

No at risk
$\begin{array}{rllllllllllllllll}\text { A } 91 & 41 & 35 & 34 & 27 & 26 & 23 & 19 & 18 & 15 & 14 & 11 & 10 & 5 & 3 & 2 \\ \text { B } 91 & 36 & 30 & 30 & 24 & 20 & 20 & 19 & 17 & 15 & 15 & 11 & 10 & 5 & 3 & 2 \\ \text { C } 91 & 31 & 27 & 27 & 22 & 19 & 19 & 17 & 16 & 14 & 14 & 10 & 9 & 4 & 3 & 2 \\ \text { A. freedom from tachyarrhythmia } \\ \text { B. freedom from bradyarrhythmia }\end{array}$
C. freedom from overall arrhythmia

FIGURE 2. Freedom from arrhythmia after biventricular repair in patients with heterotaxy syndrome. A, Freedom from tachyarrhythmia. B, Freedom from bradyarrhythmia. C, Freedom from overall arrhythmia. 
single ventricle palliation. ${ }^{2,9-11}$ Tachyarrhythmia was associated with older age at operation, whereas the need for RVOT procedures to relieve stenosis was related to the development of bradyarrhythmias. Neither bradyarrhythmias nor tachyarrhythmias were related to the type of isomerism ( $P=.886, P=.112$, Cox proportional hazards model). The types of atrial baffling, AV valve regurgitation, and systemic and pulmonary venous anomaly were not related to the occurrence of arrhythmia. Implantation of a permanent pacemaker was more common with left atrial isomerism (13/66, $19.7 \%$ ) than right atrial isomerism $(1 / 9,11.1 \%)$, but this difference was not statistically significant $\left(P=.538, \chi^{2}\right)$.

The need for reintervention and/or reoperation was also quite common among this patient population. Pulmonary stenosis $(P=.001)$, pulmonary atresia $(P=.002)$, and the presence of a common AV valve $(P=.008)$ were statistically significant risk factors for the need for reintervention and reoperation. Among the 20 patients with pulmonary stenosis, only 3 received transannular patches. Of these 3 , 2 required subsequent reoperation for the insertion of a pulmonary valve or valved conduit, and the third required catheter dilatation of the right pulmonary artery. Thus, the expected advantage of transannular patching, that is, avoidance of subsequent RVOT procedures, was not realized. Eight $(40.0 \%)$ patients underwent the reinterventions or reoperations for right ventricle-pulmonary artery conduit after biventricular repair.

Among the 36 patients with common AV valve, 14 $(38.9 \%)$ patients underwent subsequent procedures for the AV valve (such as mitral valvuloplasty in 8 , tricuspid valvuloplasty in 3 , and mitral valve replacement in 1) or permanent pacemaker insertion $(n=3)$ after biventricular repair. Our analysis identified the presence of a common AV valve as a significant risk factor for reoperation and substantiates the clinical impression that common AV valve anatomy in heterotaxy syndrome can be particularly problematic. Most of these valves are reparable but remain at risk for future intervention. ${ }^{12}$ Although the incidence of reintervention/reoperation was significant, it has not been associated with additional mortality (arrhythmia vs mortality. $P=.268$; reintervention and reoperation vs mortality, $P=.292$, Cox proportional hazards model).

The classification of heterotaxy patients on the basis of anatomic criteria is imprecise, even when the diagnosis is based on postmortem examinations. Using venous anatomic criteria for the diagnosis of heterotaxy syndrome, Van Praagh and Van Praagh ${ }^{13}$ were able to diagnose $100 \%$ of polysplenia cases but only $36 \%$ of cases with asplenia. When atrial appendage criteria were taken into consideration, only $81 \%$ of cases of asplenia fit into the expected anatomic pattern.

That being said, in our series, only 9 patients with a diagnosis of right atrial isomerism underwent biventricular repair; transposition complexes were present in 6 patients
(AV discordance in 5), CAVC in 4, DORV in 1, and pulmonary artery and pulmonary vein anomalies were common. All 9 survived biventricular repair. Although reports of biventricular repair in the setting of right atrial isomerism are rare and sporadic, ${ }^{14,15}$ most have reported relatively high mortality. ${ }^{7}$ The unsuitability of most patients with right atrial isomerism for biventricular repair is reflected by reports showing right atrial isomerism to be the predominant diagnosis in heterotaxy patients undergoing the Fontan operation. In our experience, biventricular repair for right atrial isomerism is uncommon but can be considered for carefully selected patients.

When considering a surgical strategy for heterotaxy patients, we ${ }^{16-18}$ have pursued biventricular repair in the presence of two ventricles of adequate volume and function, and septatable AV valves and venoatrial connections. Although the presence of adequate anatomic components identified above is a prerequisite for successful biventricular repair, they do not demand it. Despite the presence of favorable anatomic components, some patients with complex combined lesions may not be amenable to a biventricular repair. ${ }^{18,19} \mathrm{It}$ is important to recognize that patient selection is an important determinant of success. Given the extent of the anatomic variability of these patients, there are no clear criteria to determine suitability for biventricular repair for these patients, and each has to be considered on an individual basis. However, our findings that AV valve regurgitation and anomalous pulmonary venous connections do not place a patient at risk for mortality after biventricular repair (as opposed to the Fontan operation) should be taken into consideration when considering the surgical options for borderline cases.

In summary, biventricular repair for selected patients with heterotaxy who have favorable anatomy results in excellent survival and NYHA functional status. Long-term morbidities, including arrhythmia and reoperation/reintervention, remain common.

\section{References}

1. Bartz PJ, Driscoll DJ, Dearani JA, Puga FJ, Danielson GK, O'Leary PW, et al. Early and late results of the modified Fontan operation for heterotaxy syndrome: 30 years of experience in 142 patients. J Am Coll Cardiol. 2006;48: 2301-5

2. Stamm C, Friehs I, Duebener LF, Zurakowski D, Mayer JE Jr, Jonas RA, et al Improving results of the modified Fontan operation in patients with heterotaxy syndrome. Ann Thorac Surg. 2002;74:1967-78

3. Azakie A, Merklinger SL, Williams WG, Van Arsdell GS, Coles JG, Adatia I. Improving outcomes of the Fontan operation in children with atrial isomerism and heterotaxy syndromes. Ann Thorac Surg. 2001;72:1636-40.

4. Delius RE, Rademecker MA, de Leval MR, Elliott MJ, Stark J. Is a high-risk biventricular repair always preferable to conversion to a single ventricle repair? J Thorac Cardiovasc Surg. 1996;112:1561-8.

5. Hirooka K, Yagihara T, Kishimoto H, Isobe F, Yamamoto F, Nishigaki K, et al Biventricular repair in cardiac isomerism: report of seventeen cases. $J$ Thorac Cardiovasc Surg. 1995;109:530-5.

6. Ichikawa H, Sawa Y, Fukushima N, Ishizaka T, Iwai S, Kondo H, et al. Late assessment after biventricular repair for isomerism heart. Ann Thorac Surg. 2005 80:50-5.

7. Koh M, Yagihara T, Uemura H, Kagisaki K, Hagino I, Ishizaka T, et al. Biventricular repair for right atrial isomerism. Ann Thorac Surg. 2006;81:1808-16. 
8. Takeuchi K, McGowan FX Jr, Bacha EA, Mayer JE Jr, Zurakowski D, Otaki M, et al. Analysis of surgical outcome in complex double-outlet right ventricle with heterotaxy syndrome or complete atrioventricular canal defect. Ann Thorac Surg. 2006;82:146-52.

9. Kim SJ, Kim WH, Lim HG, Lee CH, Lee JY. Improving results of the Fontan procedure in patients with heterotaxy syndrome. Ann Thorac Surg. 2006;82: 1245-51.

10. Dickinson DF, Wilkinson JL, Anderson KR, Smith A, Ho SY, Anderson RH. The cardiac conduction system in situs ambiguus. Circulation. 1979;59: 879-85.

11. Ho SY, Fagg N, Anderson RH, Cook A, Allan LD. Disposition of the atrioventricular conduction tissues in the heart with isomerism of the atrial appendages: its relation to congenital heart block. J Am Coll Cardiol. 1992;20:904-10.

12. Hancock Freisen CL, Sherwood MC, Gauvreau K, Frank DF, del Nido PJ, Jonas RA, et al. Intermediate outcomes of atrioventricular valvuloplasty in lateral tunnel Fontan patients. J Heart Valve Dis. 2004;13:962-71.

13. Van Praagh R, Van Praagh S. Atrial isomerism in the heterotaxy syndromes with asplenia, or polysplenia, or normally formed spleen: an erroneous concept. Am J Cardiol. 1990;66:1504-6.

14. Sinzobahamvya N, Arenz C, Brecher AM, Urban AE. Atrial isomerism: a surgical experience. Cardiovasc Surg. 1999;7:436-42.

15. van Son JA, Black MD, Haas GS, Falk V, Hambsch J, Onnasch JF, et al. Extracardiac repair versus intracardiac baffle repair of complex unroofed coronary sinus. Thorac Cardiovasc Surg. 1998;46:371-4.

16. Sapire DW, Ho SY, Anderson RH, Rigby ML. Diagnosis and significance of atrial isomerism. Am J Cardiol. 1986;58:342-6.

17. Marcelletti C, Di Donato R, Nijveld A, Squitieri C, Bulterijs AH, Naeff M, et al. Right and left isomerism: the cardiac surgeon's view. Ann Thorac Surg. 1983;35: 400-5.

18. Freedom RM, Van Arsdell GS. Biventricular hearts not amenable to biventricular repair. Ann Thorac Surg. 1998;66:641-3.

19. Yun TJ, Al-Radi OO, Adatia I, Caldarone CA, Coles JG, Williams WG, et al. Contemporary management of right atrial isomerism: effect of evolving therapeutic strategies. J Thorac Cardiovasc Surg. 2006;131:1108-13.

\section{Discussion}

Dr Marshall L. Jacobs (Philadelphia, $P$ a). Thank you, Dr Pigula, for sharing this wealth of information with us. To you and your associates, congratulations on the very fine results with these difficult patients.

In 2002 I had the privilege of discussing a paper from the same institution titled "Improving Results of the Modified Fontan Operation in Patients with Heterotaxy Syndrome" (Ann Thorac Surg. 2002;74:1967-78). Dr Christof Stamm at that time reported the results of 135 Fontan procedures. Nearly three fourths of them were in the decade between 1990 and 2000. Right isomerism predominated over left, which was the opposite of your pattern of predominance in the current series. For patients after 1991, in the Fontan series, the early mortality was just $3 \%$, which is very similar to yours, and the Kaplan-Meier 10-year survival was 93\%, which is identical to what you have shown. The risk factors for mortality were anomalous pulmonary venous connection and increased pulmonary vascular resistance. Not surprisingly, in the Fontan group, the previous bidirectional Glenn anastomosis had a positive impact on survival.

Today you have shown us the other side of the coin-91 heterotaxy patients who underwent two-ventricle repair during a time interval when, according to your manuscript, an additional 280 heterotaxy patients underwent Fontan operations. The only risk factor in your series for mortality was unbalanced AV canal defect. The survivors tended to be younger patients. Freedom from arrhythmia was $60 \%$ at 5 years and $55 \%$ at 10 years. Freedom from reoperation and reintervention were actually considerably less for the biventricular repair group than for the Fontan cohort if one excludes device closure of fenestrations.
At follow-up in your series, the vast majority of patients undergoing biventricular repair were in NYHA functional class I, despite the relatively high incidence of reinterventions and arrhythmias. This was considerably higher than the fraction of the Fontan patients in NYHA class I.

My first question is as follows:

Your manuscript includes the statement: "Patients with unbalanced complete atrioventricular canal are a high-risk group for which selection criteria are particularly important.' You point out that the patients in that diagnostic group were believed by the cardiologists to have mildly unbalanced CAVC, and only 1 patient had undergone a bidirectional Glenn before biventricular repair. Another patient underwent a bidirectional Glenn as part of a subsequent re-repair or bailout. What criteria would you now apply to determine the best pathway for patients with mild ventricular imbalance? If those criteria are still illusive, might there be a greater role for staging with a bidirectional Glenn that could culminate in a biventricular repair or even a one-and-a-half ventricle repair?

Dr Pigula. Thank you for your comments. You are absolutely right. The unbalanced ventricle has been the problematic patient group, and it is not problematic just in this situation, of course.

When we evaluate these patients, we look at the typical anatomy, or the typical components of the anatomy. For biventricular repair we should require that the ventricle be of adequate size, possess adequate function, have adequate dedicated AV valve tissue, and adequate outflow tracts.

Now, quantifying those points is where it becomes difficult. That is where an overall evaluation of the composite anatomy, rather than the component anatomy, gets to be difficult. It is a matter of judgment in most cases. The fundamental issue with this kind of study, as well as the previous Fontan study out of our institution with heterotaxy, is patient selection. That is something that this paper did not address. It is a very difficult topic to try to quantify and report on, and that is why we have not been able to do that. However, I think the fundamental issue is which patients are directed toward which treatment strategy. I think that that is really exposed with the unbalanced canal defect because that is where the patients are at risk. Thus I do not have a discrete or a definite answer for you in terms of using criteria $\mathrm{A}, \mathrm{B}$, and $\mathrm{C}$, but rather a judgment about the aggregate anatomy.

Dr Jacobs. I have just one other question. In your arrhythmia follow-up data in the paper, you mentioned that there were a number of patients who had either ventricular tachycardia or ventricular fibrillation and required radiofrequency ablation or AICD. Were those late postoperative events? Is that an ongoing risk factor for these patients? Is there any evidence that it is related to septal resection or any other aspect of septation for biventricular repair?

Dr Pigula. I do not know the answer to that, but my instinct/ intuition about it is that it is related to the amount of intracardiac work. If you compare the two series, the Fontan series and this series, certainly our freedom from arrhythmia is less than we see in the Fontan group. I think that is probably related to the amount of intracardiac work, in some cases VSD enlargement or incisions in the ventricle, and I think all of those add to it. I do think that they are going to have a greater degree of electrical instability over the long term and that will continue.

Dr Hiromi Kurosawa (Tokyo, Japan). Dr Pigula, right isomerism heart, so-called asplenia, usually has a dominant right ventricle 
with common AV valve. According to your abstract, 9 patients had right isomerism. Did you do the biventricular repair for those patients who had asplenia with common AV valve?

Dr Pigula. Most of those patients had a common AV valve. I think it was 6 patients who had a common AV valve. Also, several of those patients had L-transposition of the great vessels as well.

Dr Kurosawa. Usually the asplenia heart has a very small left ventricle and a large right ventricle, so that it is sometimes difficult to divide the right ventricle into 2 ventricles.

Dr Pigula. I think your question is septating the AV valve in this setting?

Dr Kurosawa. Yes, and also the ventricle.
Dr Pigula. Well, of course, it gets back, again, to the issue of patient selection. These patients were only accepted for biventricular repair if we thought they had septatable ventricles that we could connect to their appropriate outflow tract and a septatable valve.

I think an important point is that you can have components, those components, the AV valve, the ventricular mass and size, and the outflow tracts, that are all adequate in isolation, but when you put together a composite anatomy, they still may not add up to a biventricular repair. You may still have cases in which you have functional components, but in aggregate they are not amenable to biventricular repair. These were carefully selected patients in whom we thought we could achieve a biventricular repair. 
APPENDIX E1. Procedures before biventricular repair

\begin{tabular}{lc}
\hline \multicolumn{1}{c}{ Procedures } & No. of patients \\
\hline BT shunt & 6 \\
PA banding & 3 \\
PA banding, PPM implantation & 2 \\
PPM implantation, PDA ligation & 2 \\
CoA repair & 1 \\
Glenn shunt & 1 \\
BT shunt, PA banding & 1 \\
BT shunt, TAPVR repair & 1 \\
BT Shunt, VSD device closure & 1 \\
RV-PA conduit, PA angioplasty & 1 \\
Cor triatriatum resection, CS unroofing & 1 \\
Hemitrucus repair, BT shunt, PA angioplasty & 1 \\
BT shunt, enlargement of PV confluence for PV & 1 \\
$\quad$ obstruction & \\
TAPVR repair, PA angioplasty, RV-PA conduit, & 1 \\
$\quad$ Classic Glenn shunt & \\
\hline$B T$, Blalock-Taussig; $P A$, pulmonary artery; $P P M$, permanent pacemaker; $P D A$, pat- \\
ent ductus arteriosus; $C o A$, coarctation of aorta; $T A P V R$, total anomalous pulmonary \\
venous return; $V S D$, ventricular septal defect; $R V$, right ventricle; $C S$, coronary sinus; \\
$P V$, pulmonary vein.
\end{tabular}


APPENDIX E2. Reoperations after biventricular repair

Reoperations

No. of patients

Atrioventricular valve

MVP

PVR, MVR

MVP, AVP

MVP, TVP, ASD creation, BCPS

RVOT procedure

Conduit revision

PA banding, PPM implantation

Repair of RVOT obstruction and PAPVR

RPA plasty, RV-PA conduit, ASD creation,

ligation of aortopulmonary collaterals

PS relief, aortic root reduction

PA debanding, arch augmentation

PPM implantation

Systemic/pulmonary venous return

Connection of LSVC to RA

Division of LSVC and repair of PV stenosis

Septal defects

Residual VSD closure, TVP

Residual VSD closure, SubAS relief

3

1

1

1

1

Other

Heart Transplantation

Lobectomy of RUL for lung abscess

Ascending aorta wrapping for aortic dilatation

$\overline{M V P, \text { Mitral valvuloplasty, } P V R \text {, pulmonary valve replacement; } M V R \text {, mitral valve }}$ replacement; $M V P$, mitral valvuloplasty; $A V P$, aortic valvuloplasty; $T V P$, tricuspid valvuloplasty; $A S D$, atrial septal defect; $B C P S$, bidirectional cavopulmonary shunt; $R V O T$, right ventricular outflow tract; $P A$, pulmonary artery; $P P M$, permanent pacemaker; $P A P V R$, partial anomalous pulmonary venous return; $R P A$, right pulmonary artery; $R V-P A$, right ventricle-pulmonary artery; $P S$, pulmonic stenosis; $L S V C$, left superior vena cava; $R A$, right atrium; $P V$, pulmonary vein; $V S D$, ventricular septal defect; SubAS, subaortic stenosis; $R U L$, right upper lobe. 
APPENDIX E3. Reinterventions after biventricular repair

\begin{tabular}{|c|c|}
\hline Reinterventions & $\begin{array}{l}\text { No. of } \\
\text { patients }\end{array}$ \\
\hline Pulmonary outflow tract intervention & 9 \\
\hline RV-PA conduit balloon dilation and stent & 2 \\
\hline $\begin{array}{l}\text { RV-PA conduit balloon dilation and stent, } \\
\text { both PA balloon dilation }\end{array}$ & 1 \\
\hline $\begin{array}{l}\text { RV-PA conduit balloon dilation and stent, } \\
\text { pulmonary venous baffle dilation }\end{array}$ & 1 \\
\hline LV-PA conduit balloon dilation & 1 \\
\hline RVOT balloon lation & 1 \\
\hline RVOT balloon dilation, pulmonary valve balloon valvulolasty & 1 \\
\hline Right PA balloon angioplasty for pulmonary thrombus & 1 \\
\hline Both PA balloon dilation and stent for severe both PA stenosis & 1 \\
\hline Defect closure & 4 \\
\hline VSD closure & 2 \\
\hline VSD closure, left PA dilation and stent & 1 \\
\hline $\begin{array}{l}\text { Closure of fenestrated ASD and residual } \\
\text { VSD, transvenous AICD placement }\end{array}$ & 1 \\
\hline Antiarrhythmic procedures & 4 \\
\hline Transvenous PPM & 3 \\
\hline Radiofrequency ablation for VT focus in RVOT & 1 \\
\hline Valvuloplasty & 2 \\
\hline Mitral valve balloon dilation for MS & 1 \\
\hline TV balloon dilation for mild TS, ASD balloon occlusion & 1 \\
\hline Others & 2 \\
\hline Coil embolization of APCs to RUL & 1 \\
\hline Pericardiocentesis & 1 \\
\hline
\end{tabular}

